\title{
New developments in canine hepatozoonosis in North America:
} a review

\author{
Susan E Little*, Kelly E Allen, Eileen M Johnson, Roger J Panciera, \\ Mason V Reichard, Sidney A Ewing
}

Address: Department of Veterinary Pathobiology, Center for Veterinary Health Sciences, Oklahoma State University, Stillwater, OK, USA

Email: Susan E Little* - susan.little@okstate.edu; Kelly E Allen - kelly.allen@okstate.edu; Eileen M Johnson - eileen.johnson@okstate.edu; Roger J Panciera - roger.panciera@okstate.edu; Mason V Reichard - mason.reichard@okstate.edu; Sidney A Ewing - sidney.ewing@okstate.edu

${ }^{*}$ Corresponding author

from 4th International Canine Vector-Borne Disease Symposium Seville, Spain. 26-28 March 2009

Published: 26 March 2009

Parasites \& Vectors 2009, 2(Suppl I):S5 doi:I0.II86/I756-3305-2-SI-S5

This article is available from: http://www.parasitesandvectors.com/content/2/SI/S5

(C) 2009 Little et al; licensee BioMed Central Ltd.

This is an Open Access article distributed under the terms of the Creative Commons Attribution License (http://creativecommons.org/licenses/by/2.0), which permits unrestricted use, distribution, and reproduction in any medium, provided the original work is properly cited.

\begin{abstract}
Canine hepatozoonosis is caused by Hepatozoon canis and Hepatozoon americanum, apicomplexan parasites transmitted to dogs by ingestion of infectious stages. Although the two agents are phylogenetically related, specific aspects, including characteristics of clinical disease and the natural history of the parasites themselves, differ between the two species. Until recently, H. canis infections had not been clearly documented in North America, and autochthonous infection with $\mathrm{H}$. americanum has yet to be reported outside of the southern United States. However, recent reports demonstrate $H$. canis is present in areas of North America where its vector tick, Rhipicephalus sanguineus, has long been endemic, and that the range of $\mathrm{H}$. americanum is likely expanding along with that of its vector tick, Amblyomma maculatum; co-infections with the two organisms have also been identified. Significant intraspecific variation has been reported in the I8S rRNA gene sequence of both Hepatozoon spp.-infecting dogs, suggesting that each species may represent a complex of related genogroups rather than well-defined species. Transmission of $H$. americanum to dogs via ingestion of cystozoites in muscle of infected vertebrates was recently demonstrated, supporting the concept of predation as a means of natural transmission. Although several exciting advances have occurred in recent years, much remains to be learned about patterns of infection and the nature of clinical disease caused by the agents of canine hepatozoonosis in North America.
\end{abstract}

\section{Background}

Hepatozoon canis has long been recognised to infect and cause disease in dogs in Asia, southern Europe, the
Middle East, Africa and South America. In 1978, cases of hepatozoonosis were recognised for the first time in the southern United States and initially attributed to a more 
pathogenic strain of $H$. canis [1]. However, subsequent work demonstrated that the causative agent was a distinct species, $H$. americanum, and the disease induced became known as American canine hepatozoonosis [2-6]. The life cycle of both $H$. canis and $H$. americanum involves a tickdefinitive host, where fertilisation, oocyst formation and sporogony occur, and a canine or other mammalian intermediate host, in which merogony and gamont formation occurs [7]. Gamonts are acquired by ticks during feeding, but sporozoites are released to infect the intermediate host only upon ingestion of the infected tick itself [8]. Although somewhat similar in overall life cycle, the two Hepatozoon spp. reported from dogs differ in several ways, including aspects of the clinical disease they cause in dogs, the species of tick used as a definitive host and their geographic distribution.

\section{Clinical features of canine hepatozoonoses}

Dogs with American canine hepatozoonosis present with severe, febrile disease characterised by lethargy, myalgia, lameness and mucopurulent ocular discharge. Radiographs may reveal periosteal proliferation of long bones. A profound neutrophilic leukocytosis is often present, but gamonts are only rarely found in blood smears [9]. In contrast, dogs with canine hepatozoonosis caused by $H$. canis are often clinically normal or develop only mild disease. With high parasitemia or in cases of co-infection with other tick-borne disease agents, dogs with $H$. canis may develop mild to severe clinical disease characterised by fever, lethargy and emaciation. Osteoproliferative lesions are only rarely described with $H$. canis infection $[10]$, and thus radiographs are usually unremarkable. Leukocyte counts are also usually normal or only slightly elevated, and gamonts are numerous, infecting as many as $100 \%$ of neutrophils observed [7].

\section{Tick vectors and geographic distribution of agents Hepatozoon americanum}

The definitive host and tick vector of $H$. americanum is Amblyomma maculatum, the Gulf Coast tick, which in North America was historically limited to areas along the Gulf Coast and southern Atlantic coast [11]. This tick has also been reported from Central America and northern South America [12]. Reports of $H$. americanum infection in dogs outside of the U.S. are lacking, although one survey of wildlife described an $18 \mathrm{~S}$ rDNA sequence $97 \%$ similar to that of $H$. americanum from a crab-eating fox from Brazil [13]. In recent decades, the range of A. maculatum has expanded northward with populations now established in areas of Oklahoma, Kansas, Kentucky and some other states $[12,14]$. In addition, H. americanum has been reported from California, Washington and Vermont [15], states outside the recognised range of the tick vector, presumably due to relocation of infected dogs from endemic areas.

\section{Hepatozoon canis}

The main vector of $H$. canis is Rhipicephalus sanguineus, the brown dog tick, although other ticks have also been reported as hosts [16-20]. Rhipicephalus sanguineus is found in temperate and tropical regions worldwide, and cases of $H$. canis have been reported from southern Europe, Asia, Africa, the Middle East and South America [7]. However, prior to 2008, H. canis had not been definitively identified in dogs or wild canids in North America. Since that time, $H$. canis has been confirmed in 30 dogs in the United States by PCR, 14 of which were also infected with $H$. americanum $[15,21]$, and identified in 5 dogs on the Caribbean island of Grenada [22]. Gamonts, presumably $H$. canis, were also identified on blood smear from one dog from the U.S. that had been PCR-confirmed as infected with $H$. canis, but not H. americanum [15]. Infection has also been identified by sequence-confirmed PCR in a grey fox from Georgia (M. Yabsley, pers. comm.), further supporting the interpretation that this organism is present and actively transmitted to canids in North America.

\section{Intraspecific variation}

The only Hepatozoon species described from dogs to date are $H$. canis and $H$. americanum; both have variation in reported $18 \mathrm{~S}$ rRNA gene sequences [21,23]. Although complete sequence data is available from only 2 dogs, identity among the $18 \mathrm{~S}$ rDNA fragments reported from dogs infected with $H$. americanum ranges from $92.7-99.6 \%$ [21]. Among $H$. canis sequences, the identity reported is $97-100 \%$ [21,23]. Although strain variations likely account for the differences in sequence of $18 \mathrm{~S}$ rRNA gene, the genogroup clusters from the sequence data available to date do not appear to correspond with geographic location of the dogs or severity of disease seen (data not shown). Acquisition of larger data sets with detailed information on clinical and travel history of the dogs will be necessary to more fully understand the significance, if any, of the sequence variation seen.

\section{Novel transmission routes}

In both the $H$. canis and $H$. americanum systems, dogs have been shown capable of infecting immature ticks with gamonts that develop to infectious oocysts and are able to infect a new dog upon ingestion [24]. For H. canis, dogs are likely the preeminent reservoir host because the preferred vector tick, $R$. sanguineus, feeds preferentially on dogs in all three active life stages [25]. A variety of species of fox have also been reported infected with $H$. canis [13], and thus wild canids may play a role in maintaining a source of infection in nature. In contrast, immature A. maculatum are more frequently found feeding on ground-dwelling birds, rodents and rabbits than on canids, although all three stages have been reported from coyotes [11]. Infection of wild coyotes with H. americanum 
in A. maculatum-endemic areas has been documented $[26,27]$. Coyotes have been shown to be experimentally susceptible to infection and disease and are capable of infecting immature ticks $[27,28]$. However, the predominance of immature $A$. maculatum on other vertebrate species led to persistent questions about the role hosts other than canids may play in creating a source of infection for ticks $[6,9]$.

Results from recent experiments confirm the validity of these suspicions. Ingestion of $H$. americanum sporozoites was shown to lead to the development of cystozoites in muscle tissue of cotton rats [29]. Muscle from infected rats was infectious to a dog, inducing the characteristic clinical disease of American canine hepatozoonosis [30]. Similar experiments with $H$. americanum in the past using muscle from infected dogs failed to result in transmission $[2,31]$, and although monozoic cysts have been described in dogs infected with H. canis [32], to our knowledge no feeding experiments to evaluate their infectivity have been reported. Despite testing a number of animals in endemic areas, naturally occurring infection with $H$. americanum in wild rodents, rabbits or vertebrates other than canids has not yet been demonstrated ([33]; K. Allen, unpub. data), but evidence is mounting to support the role of wild vertebrates as an important paratenic host for this parasite. Transplacental infection has also been shown to occur with $H$. canis [34], but this transmission route has not been seen in $H$. americanum.

\section{Conclusions}

Although these new data are exciting, many important questions remain about canine hepatozoonosis in North America. The variation in $18 \mathrm{~S}$ rDNA sequence reported from infected dogs suggests that multiple strains or species of Hepatozoon, which could vary in their pathogenicity and life history patterns, may be infecting and causing disease in dogs [21]. Discovery of an infectious cystozoite stage in rodents suggests vertebrates other than canids could prove to be important in maintaining $H$. americanum infections in nature by serving as paratenic hosts that infect dogs through predation $[29,30]$; the ability of other vertebrates to infect immature ticks remains to be determined, as does the role, if any, of the monozoic cyst form described in dogs with $H$. canis [32] in transmitting infection. In addition, defining the extent to which $H$. canis infects dogs in North America is of great interest. In contrast to those caused by $H$. americanum, $H$. canis infections are often clinically inapparent, particularly in otherwise healthy dogs [7], and thus this agent may be more common in dogs in this region than currently realised. The presence of a number of other endemic tick-borne infections, including anaplasmosis, babesiosis, borreliosis, ehrlichiosis and Rocky Mountain spotted fever [35-37], provides ample opportunity for co- infection and more severe disease. The agents of hepatozoonosis, like those of other vector-borne diseases, present international challenges; these important questions can be addressed only through sustained collaboration between veterinarians and parasitologists worldwide with expertise in $H$. canis and $H$. americanum.

\section{Competing interests}

Dr. Little (SEL) receives financial support for her research on ticks and tick-borne diseases from the veterinary pharmaceutical industry, the National Institutes of Health (USA) and private foundations.

\section{Authors' contributions}

This work reviews recent findings from a collaborative effort among researchers at Oklahoma State University that identify and characterise Hepatozoon sp. infections in dogs and other animals with molecular techniques (SEL, KEA) and classical studies to describe lesions and parasite life stages in vertebrate and invertebrate hosts and identify the role of wild vertebrates in the maintenance and transmission of $H$. americanum (EMJ, MVR, RJP, SAE).

\section{Acknowledgements}

The research findings reviewed in this article were supported by the KrullEwing Endowment in Veterinary Parasitology at Oklahoma State University as well as intramurally through the Center for Veterinary Health Sciences, Oklahoma State University.

This article is published as part of Parasites \& Vectors Volume 2 Supplement I, 2009: Proceedings of the 4th International Canine Vector-Borne Disease Symposium. The full contents of the supplement are available online at http://www.parasitesandvectors.com/supplements/2/SI.

Publication of the supplement has been sponsored by Bayer Animal Health $\mathrm{GmbH}$.

\section{References}

I. Craig TM, Smallwood JE, Knauer KW, McGrath JP: Hepatozoon canis infection in dogs: clinical, radiographic and hematological findings. JAVMA 1978, I73:967-972.

2. Vincent-Johnson NA, Maclntire DK, Lindsay DS, Lenz SD, Baneth G, Shkap V, Blagburn BL: A new Hepatozoon species from dogs: description of the causative agent of canine hepatozoonosis in North America. J Parasitol 1997, 83: I I 65- I I 72.

3. Mathew JS, Van Den Bussche RA, Ewing SA, Malayer JR, Latha BR, Panciera RJ: Phylogenetic relationships of Hepatozoon (Apicomplexa: Adeleorina) based on molecular, morphologic, and life-cycle characters. J Parasitol 2000, 86:366372.

4. Panciera RJ, Mathew JS, Cummings CA, Duffy JC, Ewing SA, Kocan AA: Comparison of tissue stages of Hepatozoon americanum in the dog using immunohistochemical and routine histologic methods. Vet Pathol 200I, 38:422-426.

5. Ewing SA, Mathew JS, Panciera RJ: Transmission of Hepatozoon americanum (Apicomplexa:Adeleorina) by Ixodids (Acari: Ixodidae). J Med Entomol 2002, 39:63I-634.

6. Ewing SA, Panciera RJ: American canine hepatozoonosis. Clin Microbiol Rev 2003, 16:688-697.

7. Baneth G, Vincent-Johnson N: Hepatozoonosis. In: Arthorpod-borne infectious diseases of the dog and cat. Edited by Shaw SE, Day MJ: Lippincott Williams \& Wilkins; 2005:78-88.

8. Baneth G, Samish M, Shkap V: Life cycle of Hepatozoon canis (Apicomplexa: Adeleorina: Hepatozoidae) in the tick 
Rhipicephalus sanguineus and domestic dog (Canis familiaris). J Parasitol 2007, 93:283-299.

9. Panciera RJ, Ewing SA: American canine hepatozoonosis. Anim Health Res Rev 2003, 4:27-34.

10. Marchetti V, Lubas G, Baneth G, Modenato M, Mancianti F: Hepatozoonosis in a dog with skeletal involvement and meningoencephalomyelitis. Vet Clin Pathol 2009, epub ahead of print.

II. Williams HR: The biology and zoogeography of the Gulf Coast tick, Amblyomma maculatum, the potential vector of Ehrlichia ruminantum in the United States. Texas A\&M Dissertation. PhD Thesis, Department of Entomology, Texas A\&M University, College Station, Texas; 2002:181.

12. Estrada-Pena A, Venzal JM, Mangold AJ, Cafrune MM, Guglielmone AA: The Amblyomma maculatum tick group: diagnostic characters, description of the larva of $A$. parvitarsum, 16S rDNA sequences, distribution, and hosts. Syst Parasitol 2005, 60:99-I I 2.

13. Criado-Fornelio A, Ruas JL, Casado N, Farias NAR, Soares MP, Müller G, Brum JGW, Berne MEA, Buling-Saraña A, Barba-Carretero JC: New molecular data on mammalian Hepatozoon species (Apicomplexa: Adeleorina) from Brazil and Spain. J Parasitol 2006, 92:93-99.

14. Sumner JW, Durden LA, Goddard J, Stromdahl EY, Clark KL, Reeves RK, Paddock CD: Gulf Coast ticks (Amblyomma maculatum) and Rickettsia parkeri, United States. EID 2007, 1 3:75|-753.

15. Li Y, Wang C, Allen K, Little S, Ahluwalia S, Gao D, Kaltenboeck B: Diagnosis of canine Hepatozoon spp. infection by quantitative PCR. Vet Parasit 2008, 157:50-58.

16. Baneth G, Shkap V, Presentey BZ, Pipano E: Hepatozoon canis: the prevalence of antibodies and gametocytes in dogs in Israel. Vet Res Commun 1996, 20:4106.

17. McCully RM, Basson PA, Bigalke RD, DeVos V, Young E: Observations on naturally acquired hepatozoonosis of wild carnivores and dogs in the Republic of South Africa. Onderstepoort J Vet Sci I 975, 42:117-134.

18. Murata $T$, Inoue $M$, Taura $\mathrm{Y}$, Nakama $\mathrm{S}$, Abe $\mathrm{H}$ and Fujisaki $\mathrm{K}$ : Detection of Hepatozoon canis oocysts from ticks collected from the infected dogs. J Vet Med Sci 1995, 57: I II-I I 2.

19. Craig TM: Hepatozoonosis. In: Infectious Diseases of the Dog and Cat 2nd Edition. Edited by Greene CE. Philadelphia: W.B. Saunders; 1998:458-465.

20. O'Dwyer LH, Massard CL and Pereira de Souza JC: Hepatozoon canis infection associated with dog ticks of rural areas of Rio de Janeiro State, Brazil. Vet Parasit 200I, 94:I43-I 50.

21. Allen KE, Li Y, Kaltenboeck B, Johnson EM, Reichard MV, Panciera RJ, Little SE: Diversity of Hepatozoon species in naturally infected dogs in the southern United States. Vet Parasitol 2008, 154:220225.

22. Yabsley MJ, McKibben J, Macpherson CN, Cattan PF, Cherry NA, Hegarty BC, Breitschwerdt EB, O'Connor T, Chandrashekar R, Paterson T, Perea ML, Ball G, Friesen S, Goedde J, Henderson B, Sylvester W: Prevalence of Ehrlichia canis, Anaplasma platys, Babesia canis vogeli, Hepatozoon canis, Bartonella vinsonii berkhoffii, and Rickettsia spp. in dogs from Grenada. Vet Parasitol 2008, I 5 I:279-285.

23. Karagenc TI, Pasa S, Kirli G, Hosgor M, Bilgic HB, Ozon YH, Atasoy A, Eren $H$ : A parasitological, molecular and serological survey of Hepatozoon canis infection in dogs around the Aegean coast of Turkey. Vet Parasitol 2006, I35: I I3-I I 9.

24. Mathew JS, Ewing SA, Panciera RJ, Woods JP: Experimental transmission of Hepatozoon americanum Vincent-Johnson et al., 1997 to dogs by the Gulf Coast tick, Amblyomma maculatum Koch. Vet Parasitol 1998, 80: I-I4.

25. Dantas-Torres F: The brown dog tick, Rhipicephalus sanguineus (Latreille, 1806) (Acari: Ixodidae): from taxonomy to control. Vet Parasitol 2008, I 52: 173-185.

26. Kocan AA, Breshears M, Panciera RJ, Ewing SA, Barker RW: Naturally occurring hepatozoonosis in coyotes from Oklahoma. J Wild Dis 1999, 35:86-89.

27. Kocan AA, Cummings CA, Panciera RJ, Mathew JS, Ewing SA, Barker RW: Naturally occurring and experimentally transmitted Hepatozoon americanum in coyotes from Oklahoma. JWild Dis 2000, 36:149-153.

28. Garrett JJ, Kocan AA, Reichard MV, Panciera RJ, Bahr RJ, Ewing SA: Experimental infection of adult and juvenile coyotes with domestic dog and wild coyote isolates of Hepatozoon americanum (Apicomplexa:Adeleorina). JWild Dis 2005, 41:588592.

29. Johnson EM, Allen KE, Breshears MA, Panciera RJ, Little SE, Ewing SA: Experimental transmission of Hepatozoon americanum to rodents. Vet Parasit 2007, I 5 I:I64-169.

30. Johnson EM, Allen KE, Panciera RJ, Little SE, Ewing SA: Infectivity of Hepatozoon americanum cystozoites for a dog. Vet Parasitol 2008, I 54:148-150.

31. Nordgren RM, Craig TM: Experimental transmission of the Texas strain of Hepatozoon canis. Vet Parasitol 1984, 16:207-2 I4.

32. Baneth G, Shkap V: Monozoic cysts of Hepatozoon canis.J Parasitol 2003, 89:379-38I.

33. Johnson EM, Allen KE, Panciera RJ, Ewing SA, Little SE, Reichard MV: Field survey of rodents for Hepatozoon infections in an endemic focus of American canine hepatozoonosis. Vet Parasit 2007, 150:27-32.

34. Murata T, Inoue M, Tateyama S, Taura Y, Nakama S: Vertical transmission of Hepatozoon canis in dogs. J Vet Med Sci 1993, 55:867-868.

35. Dantas-Torres F: Rocky Mountain spotted fever. Lancet Infect Dis 2007, 7:724-732.

36. Bowman D, Little SE, Lorentzen L, Shields I, Sullivan MP, Carlin EP. Prevalence and geographic distribution of Dirofilaria immitis, Borrelia burgdorferi, Ehrlichia canis, and Anaplasma phagocytophilum in dogs in the United States: results of a national clinic-based serologic survey. Vet Parasitol 2009, 160: I38- I48.

37. Yeagley TJ, Reichard MV, Hempstead JE, Allen KE, Parsons LM, White MA, Little SE, Meinkoth JH: Detection of Babesia gibsoni and the canine small Babesia sp. "Spanish Isolate" in confiscated pit bull terriers. JAVMA 2009, in press. 